\title{
Interventional radiology therapies for liver cancer
}

\section{Romaric Loffroy, Louis Estivalet, Sylvain Favelier, Pierre Pottecher, Pierre-Yves Genson, Jean-Pierre Cercueil, Denis Krausé}

Department of Vascular, Oncologic and Interventional Radiology, Le2i UMR CNRS 6306, University of Dijon School of Medicine, Bocage Teaching Hospital, 21079 Dijon Cedex, France

\begin{abstract}
Hepatocellular carcinoma ( $\mathrm{HCC})$ is the fifth most frequently found primary malignant tumor in the world. Hepatic surgery and liver transplantation are considered optimal for the curative treatment of HCC. However, only $15-20 \%$ of HCCs may be surgically treated. Most of the surgically-non-eligible patients have to receive locoregional imageguided interventional treatments including intra-arterial and percutaneous ablative therapies. The goal of this paper is to review these interventional oncology approaches. Ablative therapeutic approaches include chemical therapies (such as ethanol or acetic acid injection), and thermal therapies (such as radiofrequency ablation, laser-induced thermotherapy, microwave ablation, cryoablation, and high-intensity focused ultrasound ablation). Catheter-based therapies include embolotherapy/chemotherapy-based treatments (such as transcatheter arterial chemoembolization, bland embolization, transcatheter arterial chemoinfusion, and chemoembolization with drug-eluting beads), and radiotherapy-based treatments (such as radioembolization with yttrium-90 and injection of iodine-131-labeled lipiodol). As a result of the technical development of locoregional approaches for HCC during the recent decades, the range of combined interventional therapies has been continuously extended. In this article, an evidence-based approach will be used to review the current role of interventional radiology therapies in the management of unresectable HCC.
\end{abstract}

Key words: Hepatocellular carcinoma; local ablative therapy; radioembolization; transarterial chemoembolization

\section{Address for correspondence:}

Prof. Romaric Loffroy, Department of Vascular, Oncologic and Interventional Radiology, Le2i UMR CNRS 6306, University of Dijon School of Medicine, Bocage Teaching Hospital, 14 Rue Paul Gaffarel, BP 77908, 21079 Dijon Cedex, France. E-mail: romaric.loffroy@chu-dijon.fr

Received: 25-02-2015, Accepted: 06-09-2015

\section{INTRODUCTION}

Hepatocellular carcinoma (HCC) ranks the fifth in overall frequency and fourth in annual tumor mortality. ${ }^{[1]}$ Surgical treatments including hepatic resection and liver transplantation are considered the most effective treatments of HCC. However, less than $20 \%$ of HCC can be treated surgically because of multifocal diseases, proximity of the tumor to key vascular or biliary strictures precluding a margin-negative resection and inadequate functional hepatic reserve with cirrhosis..$^{[2-4]}$ Usually,

\begin{tabular}{|l|c|}
\hline \multicolumn{2}{|c|}{ Access this article online } \\
\hline \multirow{2}{*}{ Website: } & Quick Response Code \\
\cline { 2 - 2 } http://hrjournal.net & \\
\hline & \\
DOI: & \\
10.4103/2394-5079.167439 & \\
\hline
\end{tabular}

patients with single small HCC $(\leq 5 \mathrm{~cm})$ or up to three lesions $\leq 3 \mathrm{~cm}$ are indicated for surgery. ${ }^{[5,6]}$ When surgery is precluded, interventional treatments can be used to improve the prognosis of the patients. Such therapies, which rely on imaging guidance for tumor targeting and response assessment, include various catheter-based and percutaneous ablative techniques. These minimally invasive therapies have been used mainly for palliation but have also increasingly been used with curative intent.

This is an open access article distributed under the terms of the Creative Commons Attribution-NonCommercial-ShareAlike 3.0 License, which allows others to remix, tweak, and build upon the work non-commercially, as long as the author is credited and the new creations are licensed under the identical terms.

For reprints contact: service@oaepublish.com

How to cite this article: Loffroy R, Estivalet L, Favelier S, Pottecher P, Genson PY, Cercueil JP, Krausé D. Interventional radiology therapies for liver cancer. Hepatoma Res 2016;2:1-9. 
This review outlines the current status of the most commonly used image-guided therapeutic approaches for the management of patients with HCC.

\section{INTRA-ARTERIAL CATHETER-BASED THERAPIES}

\section{Embolotherapy/chemotherapy-based therapies}

\section{Transarterial chemoembolization}

The radiological technique for tumor devascularization was developed in the 1970s. ${ }^{[7]}$ Now, it is the most widely used primary treatment for unresectable HCC. It is also the most extensively used therapy for patients on the waiting list for liver transplantation. Embolization agents, like gelatin, may be administered together with selective intra-arterial chemotherapy mixed with lipiodol (iodized oil). Doxorubicin, mitomycin, and cisplatin are commonly used anti-tumor drugs. ${ }^{[8]}$ The rationale of transarterial chemoembolization (TACE) is as follows: cytotoxic drugs achieve higher intra-tumoral concentrations when injected in the hepatic artery, and lipophilic or amphiphilic anticancer drugs, when mixed with lipiodol, are thought to be liberated progressively inside the tumor. Lipiodol, which destroys capillary beds and induces extensive necrosis in HCC with abundant blood supply, can be transported in a tumor and may remain for weeks or months, for which the absence of Kupffer cells would presumably be responsible.

Usually, lesions that are rich in arterial blood supply can be anticipated to undergo complete necrosis, while those that lack arterial blood supply have less iodine oil deposits and need other combinative therapies. The whole procedure can be repeated monthly or longer to achieve higher degree necrosis and avoid recurrence. However, the injection of cytotoxic drugs mixed with lipiodol but not followed by embolization has not shown any substantial anti-tumor effect, suggesting that ischemia plays a key role in tumor necrosis. ${ }^{[9]}$ Still, some authors reported that transcatheter arterial infusion chemotherapy had a better anti-tumor effect than TACE. ${ }^{[10]}$ With respect to the relationship between TACE and pulmonary metastasis, Lin et al. ${ }^{[11]}$ reported that TACE did not significantly increase the risk of pulmonary metastasis. Post-embolization syndrome including abdominal pain and fever is extremely frequent and fades in a few days. Complications related to aberrant arterial embolization, such as acute cholecystitis, stenosis of the biliary tract, acute pancreatitis, or gastroduodenal ulcerations have also been reported. The selection of candidates for TACE is a key point. The benefits of the procedure should not be offset by treatment-reduced liver function failure. Patients with preserved liver function and asymptomatic multinodular tumors without vascular invasion or extra-hepatic spread are indicated for TACE. ${ }^{[8]}$ Child-Pugh class $\mathrm{C}$ is considered a contraindication. ${ }^{[12]}$
TACE achieves partial responses in $15-55 \%$ of patients and significantly delays tumor progression and vascular invasion. ${ }^{[8,12-14]}$ For HCC invading the portal venous system, TACE could be an effective treatment with the 1-, 3-, and 5 -year survival rates of $42 \%, 11 \%$, and $3 \%$, respectively. ${ }^{[1]}$ Although an earlier study showed that TACE could not improve the survival of the patients, ${ }^{[12]}$ survival benefits were identified by two studies on chemoembolization. ${ }^{[13,14]}$ Overall, the effect may be considered modest.

\section{Arterial bland embolization}

Transcatheter arterial bland embolization, which simulates arterial ligation, induces tumor ischemia by disrupting the blood supply to the tumor. Advocates of this catheter-based therapy claim that bland embolization may be equally effective as TACE for palliative treatment of primary liver cancer. ${ }^{[16]}$ Despite a trend toward improved survival with TACE, no study to date has demonstrated a difference in survival between the two techniques. ${ }^{[17]} \mathrm{A}$ randomized trial comparing embolization (without chemotherapy) vs. symptomatic treatment in patients with hepatitis $\mathrm{C}$ virusrelated liver disease and Child-Pugh class A liver function failed to demonstrate a 2-year survival advantage. ${ }^{[18]}$

\section{Drug-eluting bead chemoembolization}

Drug-eluting bead (DEB)-TACE is a drug delivery system that combines the local embolization of vasculature with the release of chemotherapy into adjacent tissue. ${ }^{[19,20]}$ It is intended for use in the treatment of hyper-vascular tumors such as HCC. Its administration is similar to that of conventional TACE. Beads are composed of biocompatible polymers such as polyvinyl alcohol (PVA) hydrogel that have been sulfonated to enable the binding of chemotherapy. ${ }^{[21]}$ The beads occlude vasculature, causing embolization, and the chemotherapy is delivered locally. ${ }^{[22,23]}$

Like conventional TACE, DEB-TACE is considered a palliative option for unresectable HCC. DEB-TACE may also use as an adjunctive therapy for liver resection or as a bridge to liver transplantation, as well as before or after radiofrequency ablation (RFA). ${ }^{[24-28]}$ There are currently two types of microspheres available for drug loading: DC Bead microspheres (Biocompatibles, UK) and the recently introduced superabsorbent polymer (SAP) HepaSphere microspheres (BioSphere Medical, USA). Most of the literature involves the application of DC Bead microspheres. These microspheres are nonbiodegradable PVA microspheres that are approved for the treatment of malignant hyper-vascular tumors and loading of doxorubicin. Precision Bead (Biocompatibles, UK) microspheres are the first factory-preloaded (doxorubicin $37.5 \mathrm{mg} / \mathrm{vial}$ ) microspheres. They can be polymerized to formulate different-sized spheres, 
ranging in maximum diameter from 100 to $900 \mu \mathrm{m}$. SAP HepaSphere microspheres (BioSphere Medical) are biocompatible, hydrophilic (absorbent), non-resorbable, and acrylic copolymer microspheres designed for hepatic arterial embolization with an ability to absorb fluids at up to 64 times their dry state volume. The expansion rate is dependent on the ionic concentration of its surrounding media. The size of dry particles ranges between 50 and $200 \mu \mathrm{m}$, corresponding to an expanded size range of 200 and $800 \mu \mathrm{m}$. The SAP microspheres can be loaded with doxorubicin or cisplatin for drug delivery during TACE. ${ }^{[29]}$ Initial in vitro and in vivo studies showed encouraging results, and these microspheres now have CE mark approval for TACE of HCC in combination with doxorubicin.

DEB-TACE appears to be a relatively safe procedure, with few long-term serious complications associated with its administration. Although symptoms of post-embolization syndromes, such as fever, nausea, vomiting, and abdominal pain appears to occur in most patients, these symptoms are associated with short hospital stays averaging 2.3 days among publications, which is significantly lower than conventional TACE procedures. The most frequent major complication associated with this procedure is liver abscess, which occurred in approximately $0.75-1.58 \%$ of publications. Other complications are infrequent, although some are quite severe. Overall mortality is potentially lower than the reported values (2.06-4.74\%) because reported mortality rates include both procedure-related causes of death, such as sepsis and hepatic failure, and death secondary to progressive disease, cardiovascular disease, pulmonary embolism, and other causes. Patients selected for most of these studies are predisposed to comorbidities as a result of their diminished hepatic function and potentially other age or lifestyle-related conditions, which should be taken into consideration. ${ }^{[30]}$

The current results show that DEB-TACE produces beneficial tumor response and has exceptionally low complication rates. The technique has the potential to become an effective alternative therapy or palliative measure in the treatment of HCC, but both delivery and data collection must be standardized in order to clarify efficacy. It is a safe alternative for the treatment of unresectable HCC but is unproven as an adjunctive treatment for other standard therapies such as resection and RFA. Further investigation is essential to better define its role as an adjunct in treating HCC.

\section{Transcatheter arterial chemoinfusion}

Transcatheter arterial chemoinfusion (TACI) is a catheterbased intra-arterial therapy that traps high concentrations of chemotherapeutic agents in tumor tissues followed by minimal embolization. ${ }^{[3]}$ TACI with maximally selective catheterization and highly concentrated chemotherapy preparations minimizes the risk of hepatocellular ischemic and cytotoxic complications and maximizes chemotherapy delivered to tumor tissue. TACI with super selective catheterization, although labor intensive, has been shown to be safe. The eligibility criteria for TACI are similar to those for TACE. Portal venous thrombosis is not a contraindication. Caution should be exercised to avoid injecting large volumes $(>10 \mathrm{~mL})$ of lipiodol. Moreover, patients with poor hepatic function and tumors with diameters of $>9 \mathrm{~cm}$ have a high risk of irreversible hepatic failure. A recent retrospective study by Kim et al. ${ }^{[32]}$ compared clinical outcomes of patients treated with TACE $(n=49)$ vs. TACI $(n=61)$ in HCC patients with major portal vein occlusion. The morbidity rate was similar for both TACE (6.1\%) and TACI (6.5\%) patients, and complications were adequately managed by medical treatment. Median survival for TACE was longer than for TACI (14.9 vs. 4.4 months, respectively, $P<0.001$ ).

\section{Radiotherapy-based therapies}

Yttrium-90 radioembolization

Transarterial radioembolization (TARE) with intra-arterial injection of yttrium-90 microspheres (Y-90) is another form of hepatic arterial therapy that is available as glass (TheraSpheres; Theragenics Corp., Ottawa, Canada) or resin (Sirtex; Sirtex Medical, Wilmington, MA, USA) and can be delivered to single or multiple segments based on selective arterial cannulation. Its small size $(20-60 \mu \mathrm{m})$ results in preferential trapping in the tumor capillary bed. These spheres can safely deliver up to $150 \mathrm{~Gy}$ of $\beta$ radiation to induce tumor necrosis by radiation and microscopic embolization once they obstruct the tumor capillary bed. This limits radiation exposure to adjacent healthy tissue, given its half-life of $62 \mathrm{~h}$ and radius of action of up to $1 \mathrm{~cm}{ }^{[33]}$ Patient selection requires pretreatment procedures, including an angiogram to perform prophylactic embolization in which variant anatomy is identified to avoid non-target delivery of Y-90, and a macro-aggregated albumin scan to confirm that hepatic artery-to-lung shunting is $<16 \%$ to prevent lung injury. ${ }^{[34]}$ An advantage of this treatment over TACE is its applicability in patients with portal vein thrombosis and potential complications caused by non-target delivery of Y-90 include gastrointestinal ulcerations, pancreatitis, pneumonitis, and cholecystitis. ${ }^{[35]}$ Salem et al. ${ }^{[36]}$ recently published a comprehensive study on the long-term outcomes after intra-arterial radiotherapy for unresectable HCC. In this study, 291 patients with HCC were treated with Y-90 as part of a single-center, prospective, longitudinal cohort study. Response rate and time to progression were determined by the World Health Organization (WHO) and 
the European Association for the Study of the Liver (EASL) guidelines. Survival by stage was assessed. Univariate and multivariate analyzes were performed. Toxicities included fatigue $(57 \%)$, pain $(23 \%)$, nausea and vomiting (20\%), and $19 \%$ exhibited grade $3 / 4$ bilirubin toxicity. The 30 -day mortality rate was 3\%. Response rates were $42 \%$ and $57 \%$ based on WHO and EASL criteria, respectively. The overall time to progression was 7.9 months. Survival times differed between patients with Child-Pugh class $A$ and B disease (class A, 17.2 months; class B, 7.7 months; $P=0.002$ ). Patients with Child-Pugh class B disease who had portal venous thrombosis survived 5.6 months (95\% confidence interval, 4.5-6.7). Baseline age, sex, performance status, the presence of portal hypertension, tumor distribution, levels of bilirubin, albumin, and alphafetoprotein, and WHO/EASL response rate were important predictors of survival. While Y-90 has anti-tumor activity, controlled data comparing TARE with TACE is lacking, and its impact on survival is not well established.

\section{Intra-arterial injection of radiolabeled lipiodol}

Lipiodol is a mixture of iodized ethyl esters from the fatty acids of poppyseed oil, containing 37\% iodine by weight. It is selectively taken up by hepatic tumors when administered via the hepatic artery, and it is retained by HCC for many weeks, even up to a year, while it is cleared from normal or cirrhotic liver within 4 weeks. When injected into the hepatic artery, it travels the peribiliary plexus to the portal veins, resulting in a dual embolization. ${ }^{[37]}$ Early in the course of exploiting lipiodol's unique features, the addition of a radionuclide to this substance gave a new dimension to its clinical use. So far, most clinical research has been performed with 131I-labeled lipiodol, which is commercially available as Lipiocis (CIS Bio International, Gif sur Yvette, France). 131I-lipiodol has been used for the palliative, adjuvant, or neoadjuvant treatment of HCC. ${ }^{\text {[38] }}$ Although most studies have failed to demonstrate any survival benefits, it seems that 131I-lipiodol is much better tolerated (fewer side effects) than chemoembolization. 131I-lipiodol has the theoretical advantage that there is no particle embolization at the end of the procedure and that portal venous thrombosis is thus not a relative or absolute contraindication.

\section{PERCUTANEOUS LOCAL ABLATION THERAPIES}

\section{Chemical ablative therapies}

Percutaneous ethanol injection

One of the first methods devised to ablate liver tumors involved percutaneous ethanol injection (PEI). Several non-randomized trials in the 1990s confirmed that PEI could safely achieve complete necrosis of small HCCs, ${ }^{39-}$ ${ }^{41]}$ with 5 -year survival rates of $32-38 \%$. However, the technique suffered from the need for multiple treatment sessions, the uncertainty of the ablation zone, and a high local progression rate of $17-38 \% .{ }^{[42,43]}$ Several randomized controlled trials compared PEI vs. RFA in the treatment of small HCC. ${ }^{[44-46]}$ These trials demonstrated an approximately $20 \%$ advantage for RFA vs. PEI in overall survival at 3-4 years, mainly as a result of a much lower incidence of local tumor recurrence in the RFA group. In addition, approximately threefold fewer treatment sessions were required for RFA compared to PEI. Two recent meta-analyzes comparing RFA vs. PEI echoed these sentiments, declaring RFA superior to PEI in the treatment of small HCC. ${ }^{[47,48]}$ PEI maintains the advantage of allowing treatment of tumors near sensitive organs and tissues and avoids the problem of the "heat-sink" effect adjacent to vessels. The applicability of PEI in other situations is limited.

\section{Percutaneous acetic acid injection}

Ohnishi et al. ${ }^{[49]}$ reported percutaneous acetic acid injection (PAAI) in 1994. Acetic acid is a noxious chemical characterized by better tissue diffusion than ethanol. Usually, it is proposed as an alternative to ethanol, to decrease the number of sessions. ${ }^{\mid 50]}$ Sequential therapy with TACE and PAAI is superior to repeated PAAI alone for patients with 3-5 cm HCC. ${ }^{[51]}$ Acetic acid has a higher diffusion capacity; it is easily available and cheap. A smaller volume of acetic acid and fewer treatment sessions can achieve the same degree of tumor ablation as ethanol. ${ }^{[50]}$ In addition, PAAI, unlike PEI, helps in infiltrating the tumor septae and capsule. There is not much literature about the efficacy of PAAI in ablating HCC. ${ }^{\text {[4-51] }}$ The procedure of PAAI is similar to PEI. This amount is injected in multiple sessions (1-2 $\mathrm{mL}$ of acetic acid per tumor per session per week) using a $23 \mathrm{G}$ spinal/Chiba needle. The response to the treatment is assessed by contrast enhanced computed tomography (CECT) of the liver after 4 weeks. CECT characterizes the liver lesion better, and the residual or recurrent disease can be seen well. The ideal lesion for PEI is small $\mathrm{HCC}<3 \mathrm{~cm}$ in size. The local tumor recurrence rate is $51 \%$ at 1 year and $74 \%$ at 3 years. The survival rate at 1 and 3 years is $84 \%$ and $51 \%$, respectively. ${ }^{[50]}$ PAAI is a safe technique, with no major complications. The rare side effects include transient hemoglobinuria (but without any renal impairment), fever, right upper abdominal pain and with larger doses, segmental infarction, and metabolic acidosis can occur. ${ }^{[49-51]}$ Transient hemoglobinuria can occur immediately after tumor ablation, even after using small volumes (5-10 mL) of 50\% acetic acid and it usually clears with a few urinary voids. Precautionary alkalinization of urine by administering intravenous fluids containing bicarbonates can be helpful. 


\section{Thermal ablative therapies}

Radiofrequency ablation

Radio frequencies are the part of the electromagnetic spectrum that are bound by a low oscillation of $3 \mathrm{~Hz}$ and a high of $300 \mathrm{GHz}$. RFA refers to the coagulative necrosis of tissue as a result of heat deposition around a probe generating electromagnetic radiation within the radiofrequency spectrum. The probe (energy source) is inserted within the target lesion, and the circuit is closed by placing grounding pads on the patient's body, usually the thighs. A generator modulates the radio frequency amplitude, and the energy is locally deposited as a result of molecular frictional loss resulting in heating of the tissues around the probe tip. The eventual ablated zone geometry is a result of complex interactions that includes the type and shape of the probe, the duration of ablation, the maximum temperature reached, and the proximity of the target lesion to vessels. ${ }^{[52]}$ Computed tomographic scanning or ultrasound is used for percutaneous probe guidance, although magnetic resonance imaging (MRI) is emerging as a possible alternative. Effective ablation depends on good tissue conductivity, which allows heat transfer farther away from the probe and a larger ablation zone. Counterintuitively, a fast power increase will result in the tissue around the probe being desiccated, which limits heat conduction and the ablation zone. Therefore, slow and methodical ablation with a gradual power increase is desired. RFA of liver lesions usually takes from 10 to 30 min per lesion.

The efficacy of RFA depends on technical aspects and to a lesser extent, on patient selection. Lesion size is the most important determinant of RFA success. Lesions up to $3 \mathrm{~cm}$ can be treated effectively with reported complete ablation rates of about $90 \% .{ }^{[3-56]}$ For lesions $>3 \mathrm{~cm},{ }^{|53,57,58|}$ the efficacy of RFA decreases with increasing lesion size. Complete ablation is possible with favorable anatomy for lesions of 3-5 cm; however, beyond the $5 \mathrm{~cm}$ size, a complete response is unlikely. The rate of recurrence is nearly $0 \%$ for smaller lesions and $>50 \%$ for lesions $>5$ $\mathrm{cm}$. Another determinant of success is lesion location. Central (near the hilum) lesions should be avoided because of the risk of the central bile duct and vascular injury. Additionally, the lesions bordering a large $(>3 \mathrm{~mm}$ ) vessel may not respond because of thermal protection provided by the adjacent blood flow, a phenomenon termed "heat-sink". Survival of patients with unresectable HCC treated with RFA is reportedly $75-92 \%$ at 1 year, $80 \%$ at 2 years, $37-59 \%$ at 3 years, and $28 \%$ at 5 years. ${ }^{[33,55]}$ Even for resectable tumors, RFA appears to offer the same benefit as resection in selected patients. Survival rates for ChildPugh class A or B patients with lesions up to $3 \mathrm{~cm}$ are not different between groups treated with RFA vs. surgical resection. ${ }^{[59]}$ Liver transplantation for HCC remains the best treatment option and offers the longest survival for the approximately $10 \%$ of patients who are candidates. Treatment with RFA, while a patient is awaiting for liver transplantation, has been shown to be an independent prognostic factor for longer survival. ${ }^{[56]}$ Although ChildPugh class $C$ patients may be safely treated with RFA, a survival benefit is unlikely as life expectancy is determined by the progression of cirrhosis. On the other hand, although prospective, randomized trials are lacking, there is strong evidence that Child-Pugh class A and B patients may benefit from RFA of unresectable HCC.

Percutaneous RFA for HCC carries certain unique risks. The mortality of percutaneous liver RFA is extremely low (< 1\%). However, this assumes preserved liver function and small ablation volumes. Because most deaths after RFA are attributed to liver failure, this risk increases with larger ablation volumes and diminished liver reserve (resulting from prior hepatectomy, cirrhosis, previous ablations, and other). The overall major risks associated with liver RFA are on the order of 4-5\%. ${ }^{[56-58,60]}$ Most patients treated with RFA for HCC may be discharged home on the day of the procedure after a 3- to 6-h observation unless a complication.

RFA is also known to enhance host immune response. However, the epitopes at which enhanced immune responses occur, the impact on patient prognosis, and the functions and phenotypes of T-cells induced are still unclear. To address these issues, Mizukoshi et al. ${ }^{[61]}$ analyzed immune responses before and after RFA in 69 HCC patients using 11 tumor-associated antigens (TAA)derived peptides that were identified to be appropriate for analyzing HCC-specific immune responses. The immune responses were analyzed using enzyme-linked immunospot (ELISPOT) assays and tetramer assays using peripheral blood mononuclear cells. An increase in the number of TAA-specific T-cells detected by interferon- $\gamma$ ELISPOT assays occurred in $62.3 \%$ of patients after RFA. The antigens and its epitope at which enhanced $\mathrm{T}$ cell responses occur were diverse, and some of them were newly induced. The number of TAA-specific $\mathrm{T}$ cells after RFA was associated with the prevention of HCC recurrence, and it was clarified to be predictive of HCC recurrence after RFA by univariate and multivariate analyzes. The number of TAA-specific $T$ cells after RFA was inversely correlated with the frequency of CD14+ HLA-DR(-/low) myeloid-derived suppressor cells (MDSCs). Modification of the $\mathrm{T}$ cell phenotype was observed after RFA. The number of TAA-specific T-cells at 24 weeks after RFA was decreased. Although RFA can enhance various TAA-specific T-cell responses and the T-cells induced contribute to 
the HCC recurrence-free survival of patients, besides immunosuppression by MDSCs, the memory phenotype and lifetime of TAA-specific T-cells are not sufficient to prevent HCC recurrence completely. Additional treatments by the vaccine or immunomodulatory drugs might be useful to improve the immunological effect of RFA. ${ }^{61]}$

\section{Microwave coagulation therapy}

Microwave ablation is the term used for all electromagnetic methods of inducing tumor destruction by using devices with frequencies greater than or equal to $900 \mathrm{kHz}$. The passage of microwaves into cells or other materials containing water results in the rotation of individual molecules. This rapid molecular rotation generates and uniformly distributes heat, which is instantaneous and continuous until the radiation is stopped. Microwave irradiation creates an ablation area around the needle in a column or round shape, depending on the type of needle used and the generating power. ${ }^{[62]}$ The local effect of treatment in HCC was assessed by examining the histological changes of the tumor after microwave ablation. ${ }^{[63,64]}$ In one study, $89 \%$ of 18 small tumors were ablated completely. ${ }^{[63]}$ Coagulative necrosis with faded nuclei and eosinophilic cytoplasm were the predominant findings in the ablated areas. There were also areas in which the tumors maintained their native morphological features as if the area was fixed, but their cellular activity was destroyed as demonstrated by succinic dehydrogenase staining. One study compared microwave ablation and PEI in a retrospective evaluation of 90 patients with small HCC. ${ }^{[65]}$ The overall 5-year survival rates for patients with well-differentiated HCC treated with microwave ablation and PEI were not significantly different. However, among the patients with moderately or poorly differentiated HCC, overall survival with microwave ablation was significantly better than with PEI. In a large series including 234 patients, the 3- and 5-year survival rates were $73 \%$ and 57\%, respectively. ${ }^{|66|}$ At multivariate analysis, tumor size, the number of nodules, and Child-Pugh classification had a significant effect on survival. ${ }^{[67 \mid}$ Only one randomized trial compared the effectiveness of microwave ablation with that of RFA. ${ }^{[68]}$ Seventy-two patients with 94 HCC nodules were randomly assigned to RFA and microwave ablation groups. Unfortunately, the data in this study were analyzed with respect to lesions and not to patients. Although no statistically significant differences were observed with respect to the efficacy of the two procedures, a tendency of favoring RFA was recognized with respect to local recurrences and complications rates. ${ }^{[68]}$

\section{Laser-induced interstitial thermotherapy}

Laser-induced thermotherapy uses optical fibers to deliver high-energy laser radiation to the target lesion. Because of light absorption, temperatures of up to $150^{\circ} \mathrm{C}$ are reached within the tumor, leading to substantial coagulative necrosis. The most commonly used device for laser ablation is the Nd-YAG laser. The optical fibers are inserted directly into the lesion under MRI guidance through a percutaneously placed needle, which is removed after localization. A multi-needle approach is essential to treat large lesions successfully $(>5 \mathrm{~cm}$ ). In such tumors, treatment time can approach $1 \mathrm{~h}$. Thermocoagulation is monitored in real time under MRI, allowing accurate estimation of the actual extent of the thermal damage. The indications and contraindications of laser ablation are the same as those for RFA and microwave ablation. ${ }^{[69]}$ Laser ablation has been shown to be effective in inducing complete necrosis in HCC. Because with other ablative techniques, long-term success rates are related to tumor size, and an $82 \%$ complete response rate has been reported for lesions measuring $3.2 \mathrm{~cm}$ in diameter. In a series of 74 patients with small HCCs, survival rates at 1,3 , and 5 years were $99 \%, 48 \%$, and $15 \%$, respectively. ${ }^{[70]}$

\section{Percutaneous cryoablation}

Cryotherapy can destroy tumors directly. With different physical and chemical mechanisms of the therapy, cell death depends on the rate of cooling, absolute depth of hypothermia, the rate of thawing, the number of freezethaw cycles and delayed effects of post-thaw ischemia. Most tumor cells die at $-40{ }^{\circ} \mathrm{C}$; repeated freezing can improve the efficacy. The larger diameter of current cryoprobes and the location of tumors within the liver still limit its application. Guo et al. ${ }^{[71]}$ reported of 26 patients with HCCs of 10-14 cm in diameter receiving argon-helium cryotherapy after TACE. After this therapy, the average neoplasm necrosis rate was $28.7 \%$, significantly higher than that of TACE only.

\section{High-intensity focused ultrasound ablation}

High-intensity focused ultrasound ablation (HIFU) as a new modality for the treatment of HCC has been applied clinically. In the treatment area, all tumor cells seem to be irreversibly dead in the forms of nuclear pyknosis, debris, and dissolution. Blood sinusoids were collapsed with endothelial cell damage. ${ }^{[72]}$ In combination with TACE, HIFU gives a 1 -year survival rate of $42.9 \%$ for IVa stage patients $(P<0.05$ compared to patients receiving TACE only) and median reduction rates of $28.6 \%, 35.0 \%$, $50.0 \%$, and $50.0 \%$ of tumor sizes at $1,3,6$, and 12 months respectively. ${ }^{[73]}$ However, the need for general anesthesia and high expenses are its disadvantages.

\section{COMBINATION THERAPIES}

Both TACE and RFA have well-known limitations in terms 
of control of large tumors. The effectiveness of RFA depends on thermal necrosis and blood flow through the tumor promotes heat loss and prevents proper heating of the tumor. A strategy of combining TACE with RFA by performing TACE before RFA treatment to reduce the heat-sink effect and increase the ablation volume of the tumor was recently evaluated in a randomized study ${ }^{[74]}$ In this study, patients with tumors larger than 3 $\mathrm{cm}$ were randomized to TACE, RFA, and TACE-RFA. The combination modality was superior in median survival (TACE-RFA at 37 months, TACE at 24 months $v s$. RFA at 22 months) and rate of objective tumor response (TACE-RFA at $54 \%$, TACE at $35 \%$ vs. RFA at $36 \%$ ). The positive findings in this study represent initial evidence in support for the use of combining local regional modalities to improve outcomes in patients with unresectable tumors. Despite aggressive local treatments with this combinational strategy, recurrence, and distant metastasis continue to have a significant effect on the overall survival of patients with HCC. Therefore, studies that combine effective systemic treatment such as sorafenib with either TACE or RFA have the potential of further improving treatment outcomes. Although the combination of RFA and TACE is most commonly used, TACE has also been combined with interstitial laser photocoagulation, microwave coagulation, ethanol injection, or HIFU. ${ }^{[73,75,76]}$ On the other hand, the combination of TACE and immunotherapy or anti-angiogenesis therapy could also be an attractive field for future clinical application.

\section{CONCLUSION}

Image-guided transcatheter and ablative approaches currently play an important role in the management of patients with HCC, a role that is likely to grow even more given the rapid pace of evolution in these technologies. In selected patient populations, these approaches already offer survival rates that are comparable to that of surgery, with the added benefits of reduced morbidity and costs, improved quality of life and shortened recovery time. As the management of patients with HCC continues to evolve toward disease containment rather than a cure and locoregional targeted therapy rather than systemic approaches, image-guided techniques pose as perfectly suited methods for this direction. Results from clinical trials involving such approaches are increasingly promising, and the potential for improvement remains vast. As a result, these therapeutic approaches will undoubtedly positively impact the outcomes of patients with HCC.

\section{Financial support and sponsorship}

Nil.

\section{Conflicts of interest}

There are no conflicts of interest.

\section{REFERENCES}

1. Kew MC. Epidemiology of hepatocellular carcinoma. Toxicology 2002;181-182:35-8.

2. Liver Cancer Study Group of Japan. Primary liver cancers in Japan. Cancer 1980;45:2663-9.

3. Lai EC, Fan ST, Lo CM, Chu KM, Liu CL, Wong J. Hepatic resection for hepatocellular carcinoma. An audit of 343 patients. Ann Surg 1995;221:291-8.

4. Alsowmely AM, Hodgson HJ. Non-surgical treatment of hepatocellular carcinoma. Aliment Pharmacol Ther 2002;16:1-15.

5. Otto G, Heuschen U, Hofman WJ, Krumm G, Hinz U, Herfarth C. Survival and recurrence after liver transplantation versus liver resection for hepatocellular carcinoma: a retrospective analysis. Ann Surg 1998;227:424-32.

6. Llovet JM, Fuster J, Bruix J. Intention-to-treat analysis of surgical treatment for early hepatocellular carcinoma: resection versus transplantation. Hepatology 1999;30:1434-40.

7. Dyon D, Mouzon A, Jourde AN, Regensberg C, Frileux C. Hepatic, arterial embolization in patients with malignant liver tumours. Ann Radiol (Paris) 1974;17:593-603. (in French)

8. Llovet JM, Bruix J. Systematic review of randomized trials for unresectable hepatocellular carcinoma: chemoembolization improves survival. Hepatology 2003;37:429-42.

9. Takayasu K, Shima Y, Muramatsu Y, Moriyama N, Yamada T, Makuuchi M, Hasegawa H, Hirohashi S. Hepatocellular carcinoma: treatment with intra-arterial iodized oil with and without chemotherapeutic agents. Radiology 1987;163:345-51.

10. Sumie S, Yamashita F, Ando E, Tanaka M, Yano Y, Fukumori K, Sata M. Interventional radiology for advanced hepatocellular carcinoma: comparison of hepatic artery infusion chemotherapy and transcatheter arterial lipiodol chemoembolization. AJR Am J Roentgenol 2003;181:1327-34.

11. Lin SC, Shih SC, Kao CR, Chou SY. Transcatheter arterial embolization treatment in patients with hepatocellular carcinoma and risk of pulmonary metastasis. World J Gastroenterol 2003;9:1208-11.

12. A comparison of lipiodol chemoembolization and conservative treatment for unresectable hepatocellular carcinoma. Groupe d'Etude et de Traitement du Carcinome Hépatocellulaire. $N$ Engl J Med 1995;332:1256-61.

13. Llovet JM, Real MI, Montaña X, Planas R, Coll S, Aponte J, Ayuso C, Sala M, Muchart J, Solà R, Rodés J, Bruix J; Barcelona Liver Cancer Group. Arterial embolisation or chemoembolisation versus symptomatic treatment in patients with unresectable hepatocellular carcinoma: a randomized controlled trial. Lancet 2002;359:1734-9.

14. Lo CM, Ngan H, Tso WK, Liu CL, Lam CM, Poon RT, Fan ST, Wong J. Randomized controlled trial of transarterial lipiodol chemoembolization for unresectable hepatocellular carcinoma. Hepatology 2002;35:1164-71.

15. Uraki J, Yamakado K, Nakatsuka A, Takeda K. Transcatheter hepatic arterial chemoembolization for hepatocellular carcinoma invading the portal veins: therapeutic effects and prognostic factors. Eur $J$ Radiol 2004;51:12-8.

16. Brown KT, Nevins AB, Getrajdman GI, Brody LA, Kurtz RC, Fong Y, Blumgart LH. Particle embolization for hepatocellular carcinoma. J Vasc Interv Radiol 1998;9:822-8.

17. Cammà C, Schepis F, Orlando A, Albanese M, Shahied L, Trevisani $\mathrm{F}$, Andreone $\mathrm{P}$, Craxì A, Cottone M. Transarterial chemoembolization for unresectable hepatocellular carcinoma: meta-analysis of randomized controlled trials. Radiology 2002;224:47-54.

18. Bruix J, Llovet JM, Castells A, Montañá X, Brú C, Ayuso MC, Vilana R, Rodés J. Transarterial embolization versus symptomatic treatment in patients with advanced hepatocellular carcinoma: results of a randomized, controlled trial in a single institution. Hepatology 
1998;27:1578-83.

19. Lewis AL, Taylor RR, Hall B, Gonzalez MV, Willis SL, Stratford PW. Pharmacokinetic and safety study of doxorubicin-eluting beads in a porcine model of hepatic arterial embolization. $J$ Vasc Interv Radiol 2006; 17:1335-43.

20. Lewis AL, Gonzalez MV, Lloyd AW, Hall B, Tang Y, Willis SL, Leppard SW, Wolfenden LC, Palmer RR, Stratford PW. DC bead: in vitro characterization of a drug-delivery device for transarterial chemoembolization. J Vasc Interv Radiol 2006;17:335-42.

21. Tang Y, Taylor RR, Gonzalez MV, Lewis AL, Stratford PW. Evaluation of irinotecan drug-eluting beads: a new drug-device combination product for the chemoembolization of hepatic metastases. J Control Release 2006;116:e55-6.

22. Taylor RR, Tang Y, Gonzalez MV, Stratford PW, Lewis AL. Irinotecan drug eluting beads for use in chemoembolization: in vitro and in vivo evaluation of drug release properties. Eur J Pharm Sci 2007;30:7-14.

23. Lewis AL, Gonzalez MV, Leppard SW, Brown JE, Stratford PW, Phillips GJ, Lloyd AW. Doxorubicin eluting beads - 1: effects of drug loading on bead characteristics and drug distribution. J Mater Sci Mater Med 2007;18:1691-9.

24. Aoki T, Imamura H, Hasegawa K, Matsukura A, Sano K, Sugawara Y, Kokudo N, Makuuchi M. Sequential preoperative arterial and portal venous embolizations in patients with hepatocellular carcinoma. Arch Surg 2004;139:766-74.

25. Llovet JM, Burroughs A, Bruix J. Hepatocellular carcinoma. Lancet 2003;362:1907-17.

26. Llovet JM. Treatment of hepatocellular carcinoma. Curr Treat Options Gastroenterol 2004;7:431-41.

27. Takayasu K, Arii S, Ikai I, Omata M, Okita K, Ichida T, Matsuyama Y, Nakanuma Y, Kojiro M, Makuuchi M, Yamaoka Y; Liver Cancer Study Group of Japan. Prospective cohort study of transarterial chemoembolization for unresectable hepatocellular carcinoma in 8510 patients. Gastroenterology 2006;131:461-9.

28. Livraghi T, Meloni F, Morabito A, Vettori C. Multimodal imageguided tailored therapy of early and intermediate hepatocellular carcinoma: long-term survival in the experience of a single radiologic referral center. Liver Transpl 2004;10:S98-106.

29. de Luis E, Bilbao JI, de Ciércoles JA, Martínez-Cuesta A, de Martino Rodríguez A, Lozano MD. In vivo evaluation of a new embolic spherical particle (HepaSphere) in a kidney animal model. Cardiovasc Intervent Radiol 2008;31:367-76.

30. Guan YS, Liu Y. Interventional treatments for hepatocellular carcinoma. Hepatobiliary Pancreat Dis Int 2006;5:495-500.

31. Liapi E, Geschwind JF. Intra-arterial therapies for hepatocellular carcinoma: where do we stand? Ann Surg Oncol 2010;17:1234-46.

32. Kim JH, Yoon HK, Kim SY, Kim KM, Ko GY, Gwon DI, Sung KB. Transcatheter arterial chemoembolization vs. chemoinfusion for unresectable hepatocellular carcinoma in patients with major portal vein thrombosis. Aliment Pharmacol Ther 2009;29:1291-8.

33. Kulik LM, Atassi B, van Holsbeeck L, Souman T, Lewandowski RJ, Mulcahy MF, Hunter RD, Nemcek AA Jr, Abecassis MM, Haines KG 3rd, Salem R. Yttrium-90 microspheres (TheraSphere) treatment of unresectable hepatocellular carcinoma: downstaging to resection, RFA and bridge to transplantation. J Surg Oncol 2006;94:572-86.

34. Carr BI. Hepatic arterial 90 Yttrium glass microspheres (Therasphere) for unresectable hepatocellular carcinoma: interim safety and survival data on 65 patients. Liver Transpl 2004;10:S107-10.

35. Salem R, Lewandowski R, Roberts C, Goin J, Thurston K, Abouljoud M, Courtney A. Use of yttrium-90 glass microspheres (TheraSphere) for the treatment of unresectable hepatocellular carcinoma in patients with portal vein thrombosis. J Vasc Interv Radiol 2004; 15:335-45.

36. Salem R, Lewandowski RJ, Mulcahy MF, Riaz A, Ryu RK, Ibrahim S, Atassi B, Baker T, Gates V, Miller FH, Sato KT, Wang E, Gupta R, Benson AB, Newman SB, Omary RA, Abecassis M, Kulik L. Radioembolization for hepatocellular carcinoma using yttrium-90 microspheres: a comprehensive report of long-term outcomes. Gastroenterology 2010;138:52-64.

37. Tancredi T, McCuskey PA, Kan Z, Wallace S. Changes in rat liver microcirculation after experimental hepatic arterial embolization: comparison of different embolic agents. Radiology 1999;211:177-81.

38. Geschwind JF, Artemov D, Abraham S, Omdal D, Huncharek MS, McGee C, Arepally A, Lambert D, Venbrux AC, Lund GB. Chemoembolization of liver tumor in a rabbit model: assessment of tumor cell death with diffusion-weighted MR imaging and histologic analysis. J Vasc Interv Radiol 2000;11:1245-55.

39. Shiina S, Tagawa K, Niwa Y, Unuma T, Komatsu Y, Yoshiura K, Hamada E, Takahashi M, Shiratori Y, Terano A, Omata M, Kawauchi $\mathrm{N}$, Inoue H. Percutaneous ethanol injection therapy for hepatocellular carcinoma: results in 146 patients. AJR Am J Roentgenol 1993;160:1023-8.

40. Lencioni R, Bartolozzi C, Caramella D, Paolicchi A, Carrai M, Maltinti G, Capria A, Tafi A, Conte PF, Bevilacqua G. Treatment of small hepatocellular carcinoma with percutaneous ethanol injection: analysis of prognostic factors in 105 western patients. Cancer 1995;76:1737-46.

41. Livraghi T, Giorgio A, Marin G, Salmi A, de Sio I, Bolondi L, Pompili M, Brunello F, Lazzaroni S, Torzilli G, Zucchi A. Hepatocellular carcinoma and cirrhosis in 746 patients: long-term results of percutaneous ethanol injection. Radiology 1995;197:101-8.

42. Hasegawa S, Yamasaki N, Hiwaki T, Sako K, Komorizono Y, Baba Y, Imamura Y, Kubozono O, Yoshida A, Arima T. Factors that predict intrahepatic recurrence of hepatocellular carcinoma in 81 patients initially treated by percutaneous ethanol injection. Cancer 1999;86:1682-90.

43. Koda M, Murawaki Y, Mitsuda A, Ohyama K, Horie Y, Suou T, Kawasaki H, Ikawa S. Predictive factors for intrahepatic recurrence after percutaneous ethanol injection therapy for small hepatocellular carcinoma. Cancer 2000;88:529-37.

44. Shiina S, Teratani T, Obi S, Sato S, Tateishi R, Fujishima T, Ishikawa T, Koike Y, Yoshida H, Kawabe T, Omata M. A randomized controlled trial of radiofrequency ablation with ethanol injection for small hepatocellular carcinoma. Gastroenterology 2005;129:122-30.

45. Lin SM, Lin CJ, Lin CC, Hsu CW, Chen YC. Radiofrequency ablation improves prognosis compared with ethanol injection for hepatocellular carcinoma $<$ or $=4 \mathrm{~cm}$. Gastroenterology 2004; $127: 1714-23$

46. Lencioni RA, Allgaier HP, Cioni D, Olschewski M, Deibert P, Crocetti L, Frings H, Laubenberger J, Zuber I, Blum HE, Bartolozzi C. Small hepatocellular carcinoma in cirrhosis: randomized comparison of radio-frequency thermal ablation versus percutaneous ethanol injection. Radiology 2003;228:235-40.

47. Cho YK, Kim JK, Kim MY, Rhim H, Han JK. Systematic review of randomized trials for hepatocellular carcinoma treated with percutaneous ablation therapies. Hepatology 2009;49:453-9.

48. Orlando A, Leandro G, Olivo M, Andriulli A, Cottone M. Radiofrequency thermal ablation vs. percutaneous ethanol injection for small hepatocellular carcinoma in cirrhosis: meta-analysis of randomized controlled trials. Am J Gastroenterol 2009;104:514-24.

49. Ohnishi K, Ohyama N, Ito S, Fujiwara K. Small hepatocellular carcinoma: treatment with US-guided intratumoral injection of acetic acid. Radiology 1994;193:747-52.

50. Ohnishi K. Comparison of percutaneous acetic acid injection and percutaneous ethanol injection for small hepatocellular carcinoma. Hepatogastroenterology 1998;45 Suppl 3:1254-8.

51. Huo TI, Huang YH, Wu JC, Chiang JH, Lee PC, Chang FY, Lee SD. Sequential transarterial chemoembolization and percutaneous acetic acid injection therapy versus repeated percutaneous acetic acid injection for unresectable hepatocellular carcinoma: a prospective study. Ann Oncol 2003;14:1648-53.

52. Georgiades CS, Hong K, Geschwind JF. Radiofrequency ablation and chemoembolization for hepatocellular carcinoma. Cancer $J$ 2008; 14:117-22.

53. Seidenfeld J, Korn A, Aronson N. Radiofrequency ablation of unresectable primary liver cancer. J Am Coll Surg 2002;194:813-28.

54. Yokoyama T, Egami K, Miyamoto M, Watanabe H, Hasegawa H, Iida S, Suzuki S, Nakamura Y, Okawa K, Hagiwara N, Takashima 
Y, Yoshioka M, Tajiri T, Onda M. Percutaneous and laparoscopic approaches of radiofrequency ablation treatment for liver cancer. $J$ Hepatobiliary Pancreat Surg 2003;10:425-7.

55. Guglielmi A, Ruzzenente A, Sandri M, Pachera S, Pedrazzani C, Tasselli S, Iacono C. Radio frequency ablation for hepatocellular carcinoma in cirrhotic patients: prognostic factors for survival. $J$ Gastrointest Surg 2007;11:143-9.

56. Arch-Ferrer JE, Smith JK, Bynon S, Eckhoff DE, Sellers MT, Bland KI, Heslin MJ. Radio-frequency ablation in cirrhotic patients with hepatocellular carcinoma. Am Surg 2003;69:1067-71.

57. Livraghi T, Goldberg SN, Lazzaroni S, Meloni F, Ierace T, Solbiati L, Gazelle GS. Hepatocellular carcinoma: radio-frequency ablation of medium and large lesions. Radiology 2000;214:761-8.

58. Cammà C, Di Marco V, Orlando A, Sandonato L, Casaril A, Parisi P, Alizzi S, Sciarrino E, Virdone R, Pardo S, Di Bona D, Licata A, Latteri F, Cabibbo G, Montalto G, Latteri MA, Nicoli N, Craxì A; Unità Interdipartimentale Neoplasie Epatiche (U.I.N.E) Group. Treatment of hepatocellular carcinoma in compensated cirrhosis with radio-frequency thermal ablation (RFTA): a prospective study. $J$ Hepatol 2005;42:535-40.

59. Crucitti A, Danza FM, Antinori A, Vincenzo A, Pirulli PG, Bock E, Magistrelli P. Radiofrequency thermal ablation (RFA) of liver tumors: percutaneous and open surgical approaches. J Exp Clin Cancer Res 2003;22:191-5.

60. Georgiades CS, Hong K, Geschwind JF. Pre- and postoperative clinical care of patients undergoing interventional oncology procedures: a comprehensive approach to preventing and mitigating complications. Tech Vasc Interv Radiol 2006;9:113-24.

61. Mizukoshi E, Yamashita T, Arai K, Sunagozaka H, Ueda T, Arihara F, Kagaya T, Yamashita T, Fushimi K, Kaneko S. Enhancement of tumor-associated antigen-specific $\mathrm{T}$ cell responses by radiofrequency ablation of hepatocellular carcinoma. Hepatology 2013;57:1448-57.

62. Lu MD, Chen JW, Xie XY, Liu L, Huang XQ, Liang LJ, Huang JF. Hepatocellular carcinoma: US guided percutaneous microwave coagulation therapy. Radiology 2001;221:167-72.

63. Yamashiki N, Kato T, Bejarano PA, Berho M, Montalvo B, Shebert RT, Goodman ZD, Seki T, Schiff ER, Tzakis AG. Histopathological changes after microwave coagulation therapy for patients with hepatocellular carcinoma: review of 15 explanted livers. $\mathrm{Am} \mathrm{J}$ Gastroenterol 2003;98:2052-9.

64. Yu NC, Lu DS, Raman SS, Dupuy DE, Simon CJ, Lassman C, Aswad BI, Ianniti D, Busuttil RW. Hepatocellular carcinoma: microwave ablation with multiple straight and loop antenna clusters - Pilot comparison with pathologic findings. Radiology 2006;239:269-75.

65. Seki $T$, Wakabayashi $M$, Nakagawa $T$, Imamura $M$, Tamai $T$, Nishimura A, Yamashiki N, Okamura A, Inoue K. Percutaneous microwave coagulation therapy for patients with small hepatocellular carcinoma: comparison with percutaneous ethanol injection therapy. Cancer 1999;85:1694-702.

66. Dong B, Liang P, Yu X, Su L, Yu D, Cheng Z, Zhang J. Percutaneous sonographically guided microwave coagulation therapy for hepatocellular carcinoma: results in 234 patients. AJR Am J Roentgenol 2003;180:1547-55.

67. Liang P, Dong B, Yu X, Yu D, Wang Y, Feng L, Xiao Q. Prognostic factors for survival in patients with hepatocellular carcinoma after percutaneous microwave ablation. Radiology 2005;235:299-307.

68. Shibata T, Iimuro Y, Yamamoto Y, Maetani Y,Ametani F, Itoh K, Konishi J. Small hepatocellular carcinoma: comparison of radiofrequency ablation and percutaneous microwave coagulation therapy. Radiology 2002;223:331-7.

69. Liapi E, Geschwind JF. Transcatheter and ablative therapeutic approaches for solid malignancies. J Clin Oncol 2007;25:978-86.

70. Pacella CM, Bizzarri G, Magnolfi F, Cecconi P, Caspani B, Anelli V, Bianchini A, Valle D, Pacella S, Manenti G, Rossi Z. Laser thermal ablation in the treatment of small hepatocellular carcinoma: results in 74 patients. Radiology 2001;221:712-20.

71. Guo Z, Xin WG, Liu F, Yu HP, Li BG, Guo XY, Zhang S, Fu L, Xing JZ, Zhang JY, Wang YJ, Gong B. Clinical application of Argon-helium cryotherapy system in the treatment of hepatocellular carcinoma. Chin J Radiol 2005;39:198-203.

72. Wu F, Wang Z, Chen W. Pathological study of extracorporeally ablated hepatocellular carcinoma with high-intensity focused ultrasound. Zhonghua Zhong Liu Za Zhi 2001;23:237-9. (in Chinese)

73. Wu F, Wang ZB, Chen WZ, Zou JZ, Bai J, Zhu H, Li KQ, Jin CB, Xie FL, Su HB. Advanced hepatocellular carcinoma: treatment with highintensity focused ultrasound ablation combined with transcatheteer arterial embolization. Radiology 2005;235:659-67.

74. Cheng BQ, Jia CQ, Liu CT, Fan W, Wang QL, Zhang ZL, Yi CH. Chemoembolization combined with radiofrequency ablation for patients with hepatocellular carcinoma larger than $3 \mathrm{~cm}$ : a randomized controlled trial. JAMA 2008;299:1669-77.

75. Kurokohchi K, Hosomi N, Yoshitake A, Ohgi T, Ono M, Maeta T, Kiuchi T, Matsumoto I, Masaki T, Yoneyama H, Kohi F, Kuriyama S. Successful treatment of large-size advanced hepatocellular carcinoma by transarterial chemoembolization followed by the combination therapy of percutaneous ethanol-lipiodol injection and radiofrequency ablation. Oncol Rep 2006;16:1067-70.

76. Dettmer A, Kirchhoff TD, Gebel M, Zender L, Malek NP, Panning B, Chavan A, Rosenthal H, Kubicka S, Krusche S, Merkesdal S, Galanski M, Manns MP, Bleck JS. Combination of repeated single-session percutaneous ethanol injection and transarterial chemoembolisation compared to repeated single-session percutaneous ethanol injection in patients with nonresectable hepatocellular carcinoma. World $J$ Gastroenterol 2006;12:3707-15. 